\title{
DEMAND FOR SOCIAL FARMING SERVICES IN LATVIA: DEMENTIA CARE IN RŪJIENA MUNICIPALITY
}

\author{
*Aija Zobena ${ }^{1}$, Daira Lāce ${ }^{2}$ \\ ${ }^{1}$ University of Latvia, Latvia \\ ${ }^{2}$ State Social Care Centre "Zemgale", Latvia \\ *Corresponding author's email: aija.zobena@1u.lv
}

\begin{abstract}
The aim of the study is to explore potential demand for social care services offered by social farming in Latvia by studying the experience of families caring for family members with dementia. Social farming is both a new and a traditional concept. It originates from the traditional rural self-help networks that were well established in rural areas before the modernisation of agriculture and the rise of the public welfare system. Social agriculture covers at least three dynamic areas of society - rural development, social entrepreneurship and the growing demand for social care services, and it is closely linked to the concept of multifunctional agriculture. As a form of social entrepreneurship, social farming could create the opportunity to reconnect farmers with their local communities through the opening of their farms as part of the social support system of the community. Caring for people with dementia is a particular challenge. Currently in Latvia, families where one of the family members has dementia have only two options - to place their relatives in a care institution or to take care of them in the family. Foreign experience shows that social care farms can provide care services to people with early dementia. This paper, exploring demand for these services in Latvia, is based on the case study of families caring for persons with dementia in Rūjiena municipality in April 2020. Key words: social farming, rural development, multifunctional agriculture, social entrepreneurship, dementia care.
\end{abstract}

\section{Introduction}

Social farming is an emerging topic for different stakeholders - farmers, farmers' organisations, service-users of social farms and their organisations, providers of social and health care services, other stakeholders in social and health care and local, regional and national authorities. Social farming is both a new and a traditional concept. It originated from the traditional rural self-help networks that were well established in rural areas before the modernisation of agriculture and the rise of the public welfare system. Social farming fits with the changing needs in society. It is interesting for the social and health care sectors, as it is linked to the strong demand for inclusive development coming from the fields of social and health care services. In general, social farming covers at least three dynamic areas of society - rural development, social entrepreneurship and the growing demand for social care services; it is closely linked to the concept of multifunctional agriculture.

Today's endogenous and neo-endogenous approach to rural development in Europe implies development in its broadest sense, meaning not only traditional agricultural sectors but also diversified local economies, social inclusion and the involvement of more active communities in development processes (Galdeano-Gómez, Aznar-Sánchez, \& Pérez-Mesa, 2011). Multifunctional agriculture function refers to the provision of goods and services that 'satisfy societal needs or demands' and the end consumer is also human (Wiggering et al., 2006).

Agricultural multifunctionality is closely associated with farm diversification which itself can take many various forms (Knickel \& Renting, 2000).
In rural development context social farming could be analysed as one form of diversification of farming that is becoming increasingly common in many European countries (de Krom \& Dessein, 2013). Multifunctionality, a core issue in the EU agricultural and rural development agenda, refers to the different functions that agriculture fulfils in society, functions that go well beyond the production of food and fibres (Bassi, Nassivera, \& Piani, 2016).

Rural social environment is related to peculiarities of economic structure, demographic processes. Latvia is characterized by a large number of small farms $(85 \%)$ with significant economic and social disparities, which also have a territorial impact. Small farm output and, consequently, incomes are relatively small, contributing to social stratification. The age structure of farm holders shows that in the group of small farms are twice time more owners above the age 65 years as it is in groups of medium and big farms' owners. Small farms use $43 \%$ of agricultural land with a relatively low level of production $(27 \%$ of standard output). Small farms have a relatively large number of employees $-76 \%$ of those employed in agriculture. The number of farms in Latvia is shrinking. According to the data of the Farm Register, between 2005 and 2016, the number of farms decreased from 133 thousand up to 82.4 thousand or by $38 \%$, which are mainly small farms (AREI, 2017); therefore, the acquisition of new economic activities and the diversification of income sources are important for the survival of small farms.

Small farms are an important support for the employment of the rural population, maintenance of the natural environment and traditional cultural landscapes, ensuring biodiversity. These farms create 
an aesthetic rural environment, offer new recreational and health services, produce regional cuisine, establish short food chains, operate in an environmentally friendly manner, and use organic farming methods. These farms mark new trends in rural development, such as part-time farming, lifestyle farms, pension management, educational, social care, rehabilitation, therapeutic functions, agricultural diversification, artisan food processing. (Wilson, 2007; Zasada, 2011; Braastad \& Hauge, 2007; De Krom \& Dessein, 2013). Social farming would create new employment and income opportunities, allow small farms to survive in the future. Many European countries have considerable experience in social farming - social care farms in Ireland, the Netherlands, Finland, Norway and elsewhere are successfully developing social care services. In these countries care farms develop an idea of multifunctional agriculture by organizing social services on the local level. Poland - a new member of the European Union, supported by the same legislative framework and programme objectives of the EU in the area of green care could be mentioned among these countries. Like other new members of the EU, Poland represents the country with no strong social welfare system like in Nordic countries. Poland in the programming period 2014-2020 was the biggest beneficiary of Cohesion Policy funds and therefore could afford bigger investments in social farming. This solution is quickly developing in the country (Wojcieszak, 2018).

Healthcare systems across the world are experiencing increased financial, organizational and social pressures attributable to a range of critical issues including the challenge of ageing populations. Health systems need to adapt to sustainably provided quality care to the widest range of patients, particularly to those with chronic and complex diseases, and especially to those in vulnerable and low-income groups. Referring to global demographics and technological developments, health care experts note: 'the gap between urban and rural areas continues to grow due to the disproportionate concentrations of resources and health services in cities. Ageing populations will lead to a shift of focus towards long-term and chronic care, in comparison to treatments in acute settings. To counterbalance these issues, healthcare services should ideally be decentralised and flexible, and better at coordinating efforts for patients to move from provider-centric care to primary-, communityand patient-centric care' (Amalberti, Nicklin, \& Braithwaite, 2016).

The consequences of aging population affect the entire EU due to increasing life expectancy and consistently low levels of fertility over recent decades. The trend is expected to continue in the coming decades (European Commission, 2015). The challenges that come with a rapidly aging population establish new relations between family, community and caregiver organizations (Hollinrake \&Thomas, 2015).

At the same time, entrepreneurs see new opportunities in this service sector. This is evidenced by statements such as 'seniors are the health care industry's gold rush'. Policymakers throughout Europe have worked on tackling the societal challenge of an ageing population in Europe for many years. Initially, there was a focus on maintaining public spending on health and care and pensions sustainable in the short and long term. This focus has since been extended and increasingly the challenge of an ageing population is being tackled more comprehensively as an opportunity, involving technologies and social innovations, and identifying cross-cutting solutions to improve the general health and wellbeing of the older adults. There has also been a greater recognition that while the Silver Economy represents private and public consumption that serves the needs of older people, many indirect and induced effects provide opportunities for both the older and younger generations (European Commission, 2018)

In rural development too, the aging of the population is both a challenge and an opportunity. Social farming is one the most significant examples of social innovation in rural areas. Social farming is a response to changes in agriculture and rural lifestyle in communities across rural Europe. Social farming as a form of social entrepreneurship could create the opportunity to reconnect farmers with their local communities through the opening up of their farms as part of the social support system of the community.

Caring for people with dementia is a particular challenge. Dementia is a progressive disease that affects multiple levels of functioning. People with severe cognitive impairment need help in almost all aspects of daily life, but it is important to provide appropriate care at an early stage in order to distance the patient from losing his or her functional independence and improve his or her life during illness. Foreign experience shows that social care farms can provide care services to people with early dementia, extending the time when the need arises to place them in longterm care facilities (de Boer et al., 2019). It has been reported that cognitive decline could be prevented, and the onset of Alzheimer's disease could be delayed if people with mild cognitive impairment are mentally active and frequently participate in social activities (Hsiao, Chang, \& Gean, 2018). This care model could also be suitable for Latvian conditions, especially in remote areas, where the costs of social services provided by the public sector are high and where there are many small and medium-sized farms, where social entrepreneurship would allow diversification of income. 
The experience of other countries shows that the social care services offered by social farming can ensure the sustainability of small and medium-sized farms, improve the availability of social services in remote areas. Although ensuring the quality and wide availability of these services is a key challenge in countries where the purchasing capacity of a large part of the population is low, the benefits are significant. Currently in Latvia, families where one of the family members has dementia have only two options - to place their relatives in a care institution or to take care of them in the family. Placing people with dementia in social care institutions with many clients in families is often seen as a last resort. Although family caregivers face serious difficulties, families only choose this option if family care is no longer possible.

Working with people with dementia requires holistic support and help - to maintain his social network, to strengthen his individuality, to give him the ability to self-determination, to inform him, to promote his independence and to promote factors that improve his quality of life. For people with mild cognitive impairment who are mentally active in a family environment, maintaining a normal lifestyle and moderate physical activity in social care farms may defer the need for care in institutions until later, even if there are no conditions in the family to care for them. Even if the family is willing and able to care for their family member with dementia, situations may arise where the use of services of social care farms may be necessary on a temporary basis. The aim of the study is to explore potential demand for social care services offered by social farming in Latvia by studying the experience of families caring for family members with dementia.

\section{Materials and Methods}

The core research methodology for obtaining and analysing empirical data in this qualitative study was the case study approach. This paper is based on case study of families caring for patients with dementia in Rūjiena municipality in April 2020. Case study is a research approach and a strategy that uses different methods of collecting data: quantitative, qualitative, desk study, etc. Case studies are generally characterised by the potential localisation of a specific research topic in terms of their diversity (Yin, 2014).

In this study the main research tool was in-depth explorative interviews with family caregivers taking care of persons with symptoms of dementia and diagnosed dementia. Family doctors, representatives of care institutions and other specialists involved in the care of people with dementia were also interviewed. In the interviews, the family members talked about their experience in caring for relatives with dementia and what support they would need.
Three families from Rūjiena municipality living in different circumstances were included in the study using convenience sampling.

Written or verbal consent for participation in the study was obtained from participants prior to the interview. Due to the restrictions imposed by the Covid-19 pandemic, the interviews were conducted by telephone.

\section{Results and Discussion}

Rüjiena municipality is in the northern part of Latvia, about $150 \mathrm{~km}$ from the capital Riga. In 2018 more than half $-56 \%$ - of the 5154 inhabitants of the municipality lived in town. Municipality has a relatively good infrastructure of health care and social services - two social care centres and a social care and rehabilitation institution.

A stable health care system has been established in Rüjiena region, where outpatient health services (family doctor, gynaecologist, physiotherapist, surgeon, X-ray diagnostic room) are provided. The social care system in Rūjiena consists of the municipality's Social Service agency, psychologist, private long-term care and rehabilitation centre, municipal and state care institutions. State social care centre Vidzeme branch 'Rūja' is a long-term social care institution for persons with mental disorders, and it has 270 clients. Association 'Rūjienas senioru māja' is a private long-term care and rehabilitation institution for various types of clients (a total of 100); it also offers a day-care service. Social care centre 'Lode' is a municipal long-term social care institution, which has 83 clients. In general, the population in municipality has quite good access to health and social care services.

Family composition, living conditions and level of material well-being affect the ability to care for a relative with dementia, so families living in different circumstances were included in the study.

Family No1 lives in a three-room apartment on the third floor of an apartment building. A person with dementia, a 79-year-old woman, lives with her daughter, son-in-law and granddaughter. The daughter and her husband are of working age and are at work during the day, the granddaughter is a schoolgirl. Dementia (Lewy body dementia) was diagnosed in April 2017, but the family had noticed the signs of the disease much earlier. Hallucinations are one of the main features of this form of dementia. The support of their family doctor greatly facilitates family caregivers. To maintain her functional condition, a woman attends physiotherapist classes twice a month. Significant support is provided by neighbours who are aware of the illness and, if necessary, contact family members on weekdays when the woman is left at home alone. So far, help from the municipality has not 
been necessary; however, if it is needed in the future, the family will ask for support from the municipal Social Service agency. If the woman's health condition deteriorates, she will be placed in the social care centre 'Lode'. The daughter, who cares for her mother with dementia, notes that emotional support and information about the course of the disease are most needed.

Family caregivers face an extraordinary number of challenges, from negative impacts on their physical and mental health to the expected loss of their relative: 'Sometimes it seems to me that I will soon be confused myself. There are days when I can no longer stand the emotional presence of my mother. I myself need emotional support to endure all this ... I sometimes feel guilty that it happened to my mom, I feel guilty because I didn't notice before that she already had a bad memory' (family No 1 caregiver). Relatives noted in interviews that they often feel guilty that this has happened to their loved ones and that they cannot help a person with dementia regain their previous quality of life and functional abilities. Caring for a person with dementia is emotionally hard work and involves mental strain and emotional stress, which often manifests itself as guilt, anger, pain, helplessness, and a feeling of emptiness, which often leads to burnout. Even a temporary placement of a person with dementia in a care farm would allow family caregivers to relax, arrange some important family activities.

Understanding and support from others is important for families of dementia patients: 'We have great neighbours. We can safely go to work, because we know that if my mother has left the apartment, the neighbours will call and inform. Once my mother felt that neighbours were stealing her water and she called the house manager and complained about it. The house manager informed us, and we knew what to do next. Our neighbours are a great support to us, and we do not hide from them that my mother is ill' (family No 1 caregiver).

If dementia is diagnosed as a disease, families are more likely to receive support from both the family doctors and other care professionals. However, there are often cases where only the symptoms and signs of the dementia have been identified but the disease has not been diagnosed. All family doctors who participate in the study confirm that they have patients with dementia in their practice. In family doctors' practices, there are both patients who have been diagnosed with dementia and those who have symptoms of dementia, but this diagnosis has not been established. Family doctors cite the distance to specialists who can make this diagnosis, as well as the reluctance of relatives, as the main reasons for not having a diagnosis. Dementia patients are elderly, receive an old-age pension and are not eligible for invalidity benefit.
In family No 2, an 84-year-old woman lives with her son and daughter-in-law. She has not been diagnosed with dementia although she has symptoms. The family lives in a private house outside the centre of Rüjiena. The son and his wife are both of working age and working. The son's wife's work is in shifts, she tries to arrange her work schedule so that she is at work when her husband is at home, but this is often impossible. The old woman is often alone at home during the day. She has not been diagnosed with dementia because her family doctor does not see such a need. About 1.5 years ago, the family noticed a change in the woman's behaviour and, taking care of her safety, decided that she should live with her son's family. This woman has disorientation in time and space, memory and cognitive impairment (these symptoms correspond to the fourth stage of the disease). Her daughter-inlaw works in a social care centre, where there are also clients with dementia, and the necessary information about the disease is obtained from her colleagues - a social worker and a nurse. The family has not established good contact with the family doctor, they have not sought help from the social service. Relatives turn to their family doctor only if they need to receive a prescription for medication. Daughter-inlaw mentioned that her mother-in-law last visited her family doctor about a year ago. Relatives do not want the Social Service agency to be informed that a person with dementia lives in their family. They are worried that they will then be considered a 'crazy' family. Family No 2 would like to have emotional support and a little material help.

In interviews, relatives admitted that the time when people with dementia live in families is now between one and three years. For relatives to be able to live with a person with dementia, support is needed on a daily basis. Relatives admit that now relatives, neighbours, colleagues and friends provide a lot of support - both emotional and informative.

It is very important to get emotional support from others: 'When a friend comes to me and we are together and talking, I will even forget for a moment how difficult it is for me to take care of my motherin-law. I can tell everything to my friend and then it's easier for me ... Mom doesn't want to go out of the house anywhere, but when my daughter-in-law comes in and talks to her, they both bake a cake together, then I see that mom feels better for a while, and I also feel relaxed because the daughter-in-law spends time with her.' (family No 2 caregiver). To provide quality care to people with dementia, family caregivers themselves need social interaction to regain strength and socialize with other people. Such socialization is like a moment of rest for them and an opportunity to regain strength, improve oneself and improve one's quality of life by temporarily deviating from the daily routine 
associated with caring for a person with dementia. In interviews, relatives admitted that the time when people with dementia live in families is now between one and three years. In order for relatives to be able to live with a person with dementia, support is needed on a daily basis. Relatives admit that now relatives, neighbors, colleagues and friends provide a lot of support - both emotional and informative.

Families caring for people with dementia living outside the city have very limited social contacts. Family No. 3 lives in a private house outside the city of Rūjiena (Jeru parish). The house is located on the outskirts and the nearest neighbours are about $1 \mathrm{~km}$ away. A person with dementia is a 79-year-old woman who lives with her daughter. Dementia is diagnosed as a disease by a family doctor, not a psychiatrist. The daughter has terminated her employment because she believes she needs to take care of her sick mother. The old woman has severe memory problems, cognitive impairment, disorientation in time and space, a tendency to wander around, she is unable to take care of her own hygiene. She has limited mobility - she uses a rollator. The symptoms correspond to the fifth stage of the disease. The daughter and the mother with dementia have developed a good relationship with the family doctor. The daughter hides her mother's dementia from others. They both attend church on Sundays because the daughter believes that people in the church understand her situation and support her. The daughter has a good cooperation with the family doctor and physiotherapist. She does not want to use the support of the Social Service agency. The daughter would like to receive emotional and informative support, admits that there is a lack of social contacts, but she does not want to receive any kind of support from the neighbours: 'I feel that I need people around me because being here alone with my mother on a daily basis makes my situation even more difficult' (family No 3 caregiver).

Social interactions are equally important for both the person with dementia and family caregivers. In order to provide quality care to a family member with dementia, they themselves need social interaction to regain strength by temporarily deviating from the daily routine associated with caring for a person with dementia.

However, under the influence of stereotypes and prejudices about dementia in the society, family caregivers often hide this diagnosis, isolating themselves from others: 'I am already guilty that my mother has this disease...' (family No 3 caregiver). These prejudices further increase the risk of burnout, which is already high if he or she must take care of his or her family member with dementia alone.

Although the staff tries to find the optimal solution for each situation, it is not easy for families to take decision to place their family member with dementia in a care institution. To provide support to relatives of a person with dementia, each long-term social care institution in Rūjiena municipality has developed its own approach and is improving it by adapting to the wishes and needs of each family: 'I invite relatives and the client to visit the institution before the placement to see how we work. Relatives are often emotionally tired of a person with dementia care at home. Relatives expect emotional and informative support from us. They also want information about the course and symptoms of the disease. After placement, we allow a relative to visit their loved ones as often as they wish' manager of a private long-term care centre 'Rūjienas senioru māja'). Care institutions try to maintain relationships with the client's family. State social care centre Vidzeme branch 'Rūja' manager: 'I believe that family ties play an important role so that the client, even if placed in a care institution, does not feel lonely and abandoned. Basically, it is regular communication to inform about clients' health, social activities, etc. As far as possible and if relatives are interested in, we explain how the disease affects the client's personality'.

For relatives, placing a person with dementia in a care centre is a difficult and important decision. Relatives try to provide family care as long as possible. Social care farms for people with dementia in care could be a halfway point between the family and the long-term care facility.

\section{Conclusions}

Social farming covers at least three dynamic areas of society - rural development, social entrepreneurship and the growing demand for social care services, and it is closely linked to the concept of multifunctional agriculture.

Many European countries have considerable experience in social farming. These are not only countries with strong social welfare systems, but also the new EU member states, similar to Latvia.

Foreign experience shows that social care farms can provide care services to people with early dementia, extending the time when the need arises to place them in long-term care facilities.

Currently in Latvia, families where one of the family members has dementia have only two options to place their relatives in a care institution or to take care of them in the family. Placement of people with dementia in social care institutions is often the last resort although family caregivers face serious difficulties.

Family composition, living conditions and level of material well-being affect the ability to care for a relative with dementia.

Family caregivers face an extraordinary number of challenges, from negative impacts on their physical 
and mental health to the expected loss of their relative. The situation is complicated by the fact that, due to stereotypes and prejudices about dementia in the society, family caregivers often hide this diagnosis in isolation from others.

For relatives, placing a person with dementia in a care centre is a difficult and important decision. Relatives try to provide family care for as long as possible. The services offered by social care farms would significantly improve the care of people with dementia, as they would act as a missing step between the care of these people in families and long-term care institutions.

Working with people with dementia requires holistic support and help - to maintain his social network, to strengthen his individuality, to give him the ability to self-determination, to inform him, to promote his independence and promote factors that improve his quality of life. Further research is necessary to investigate models of ensuring the quality of social care services for persons with dementia in social care farms, to develop models of financial viability of these farms.

\section{Acknowledgements}

The research was supported by the project 'Ready for change? Sustainable management of common natural resources' funded by the Latvian Council of Science (No. lzp-2019/1-0319).

\section{References}

Amalberti, R., Nicklin, W., \& Braithwaite, J. (2016). Preparing national health systems to cope with the impending tsunami of ageing and its associated complexities: towards more sustainable health care. International Journal for Quality in Health Care. 28, 412-414. DOI: 10.1093/intqhc/mzw021.

AREI (2017). Mazo un vidèjo saimniecību attīstības iespējas un ieteicamie risinājumi LAP kontekstā. Atskaite. (Development opportunities for small and medium-sized farms and recommended solutions in the context of RDP. Report). Agroresursu un ekonomikas institūts, (pp. 15-16). Retrieved March 1, 2021, from https://www.arei.lv/sites/arei/files/files/lapas/Mazo\%20un\%20videjo\%20saimniecibu_ attistiba_2017.dec_.pdf.

Bassi, I., Nassivera, F., \& Piani, L. (2016). Social farming: a proposal to explore the effects of structural and relational variables on social farm results. Agricultural and Food Economics. 4:13 DOI: 10.1186/s40100016-0057-6.

Braastad, B.O., \& Hauge, H. eds. (2007). Green care in Agriculture: Health effects, Economics and Policies. Book of abstracts of the COST Action 866 conference. 20-22 June, Vienna, Austrian Horticultural Society.

De Boer, B., Verbeek, H., Zwakhalen, S.M.G., \& Hamers, J.P.H. (2019). Experiences of family caregivers in green care farms and other nursing home environments for people with dementia: a qualitative study. $B M C$ Geriatrics, 19, 149. DOI: 10.1186/s12877-019-1163-6.

De Krom, M.P.M.M., \& Dessein, J. (2013). Multifunctionality and care farming: Contested discourses and practices in Flanders. NJAS - Wageningen Journal of Life Sciences. 64-65, 17-24. DOI: 10.1016/j. njas.2012.09.002.

European Commission (2015). Demography Report. Short Analytical Web Note 3/2015. Employment, Social Affairs \& Inclusion. Eurostat. Retrieved March 1, 2021, from http://ec.europa.eu/eurostat/ documents/3217494/6917833/KE-BM-15-003-EN-N.pdf/76dac490-9176-47bc-80d9-029e1d967af6.

European Commission (2018). Silver Economy Study: How to stimulate the economy by hundreds of millions of Euros per year. Retrieved March 1, 2021, from https://ec.europa.eu/digital-single-market/en/news/silvereconomy-study-how-stimulate-economy-hundreds-millions-euros-year.

Galdeano-Gómez, E., Aznar-Sánchez, J.A., \& Pérez-Mesa, J.C. (2011). The Complexity of Theories on Rural Development in Europe: An Analysis of the Paradigmatic Case of Almera (South-east Spain). Sociologia Ruralis, 51(1), 54-78. DOI: 10.1111/j.1467-9523.2010. 00524.x.

Hollinrake, S., \& Thomas, W. (2015). Caring Relationships and Efficient Social Care Provision: Can an Ethic of Care Provide a Better Foundation for Responding to Care Needs in Later Life? International Journal of Sociology and Social Policy, 35 (5/6), 419-436. DOI: 10.1108/IJSSP-08-2013-0089.

Hsiao, Y.-H., Chang, C.-H., \& Gean, P.-W. (2018). Impact of social relationships on Alzheimer's memory impairment: mechanistic studies. Journal of Biomedical Science, 25, 3. DOI: 10.1186/s12929-018-0404-X.

Knickel, K., \& Renting, H. (2000). Methodological and conceptual issues in the study of multifunctionality and rural development. Sociologia Ruralis, 40(4), 512-528. DOI: 10.1111/1467-9523.00164.

Wiggering, H., Dalchow, C., Glemnitz, M., Helming, K., Muller, K., Schultz, ... Zander, P. (2006). Indicators for multifunctional land use - linking socio-economic requirements with landscape potentials. Ecological Indicators, 6 (1), 238-249. DOI: 10.1016/j.ecolind.2005.08.014.

Wilson, G.A. (2007). Multifunctional agriculture: A transition theory perspective. CABI. 
Wojcieszak, M. (2018). Welfare farms in Poland as an example of entrepreneurial activities in rural areas. Proceedings of the 2018 International Scientific Conference 'Economic Sciences for Agribusiness and Rural Economy’ No 2, Warsaw, 7-8 June 2018, 161-166. DOI: 10.22630/ESARE.2018.2.20.

Yin, R.K. (2014). Case Study Research Design and Methods. (5 $5^{\text {th }}$ edition). Sage.

Zasada, I. (2011). Multifunctional peri-urban agriculture - A review of societal demands and the Provision of goods and services by farming. Land Use Policy, 28, 639-648. DOI: 10.1016/j.landusepol.2011.01.008. 